\title{
Socio-demographic, behavioural and health-related characteristics associated with active commuting in a regional Australian state: Evidence from the 2016 Tasmanian Population Health Survey
}

Oliver Stanesby ${ }^{a *}$, Michael Long ${ }^{\mathrm{b}}$, Kylie Ballc, Leigh Blizzard ${ }^{\mathrm{a}}$, Fiona Cocker $^{\mathrm{a}, \mathrm{d}}$, Stephen Greaves ${ }^{\mathrm{e}}$, Siobhan Harpurf ${ }^{\mathrm{f}}$,Fay Johnston ${ }^{\mathrm{a}, \mathrm{f}}$, Kim Jose ${ }^{\mathrm{g}}$, Elaine Marshallf, Andrew J. Palmer ${ }^{\mathrm{a}}$, Melanie Sharmana, Alison Venn ${ }^{\mathrm{a}}$, Julie Williams $^{\mathrm{f}}$, Verity Cleland $^{\mathrm{a}}$

a Menzies Institute for Medical Research, University of Tasmania, Hobart, Australia

${ }^{b}$ Epidemiology Unit, Tasmanian Department of Health, Hobart, Australia

${ }^{c}$ Institute for Physical Activity and Nutrition, Deakin University, Geelong, Australia

${ }^{d}$ School of Medicine, University of Tasmania, Hobart, Australia

e Institute of Transport and Logistics Studies, University of Sydney, Sydney, Australia

${ }^{f}$ Public Health Services, Tasmanian Department of Health, Hobart, Australia

$g$ Institute for the Study of Social Change, University of Tasmania, Hobart, Australia

* Corresponding author: Menzies Institute for Medical Research, University of Tasmania;

Private Bag 23, Hobart, Tasmania, Australia, 7001; +61 36226 4641;

oliver.stanesby@utas.edu.au; https://orcid.org/0000-0002-5996-5881

\section{Funding}

This work was supported by the National Health and Medical Research Council Australia [grant number 1152999]; National Heart Foundation [grant number 100444]; Metro

Tasmania; the Tasmanian Department of Health; and the Local Government Association of Tasmania.

\section{Role of the funding sources}

The Tasmanian Department of Health led the study design of the Tasmanian Population Health Survey, and collection and analysis of data for this manuscript, and contributed to the interpretation of data and writing of the report. All other funding sources had no role in study

This is the author manuscript accepted for publication and has undergone full peer review but has not been through the copyediting, typesetting, pagination and proofreading process, which may lead to differences between this version and the Version of Record. Please cite this article as doi: $10.1002 /$ HPJA.428

This article is protected by copyright. All rights reserved 
design; in the collection, analysis and interpretation of data; in the writing of the report; or in the decision to submit the article for publication.

\section{Acknowledgements}

This work was supported by a Partnership Project grant from the National Health and Medical Research Council Australia (1152999) and Metro Tasmania, the Tasmanian Department of Health, and the Local Government Association of Tasmania. VC is supported by a National Heart Foundation of Australia Future Leader Fellowship (100444). We acknowledge the partnership of Metro Tasmania, the Tasmanian Department of Health, and the Local Government Association of Tasmania in conducting this work. This work does not necessarily reflect the view of the organisations involved in the research. We acknowledge the Tasmanian Department of Health who provided data for this project.

\section{Conflict of interest}

The authors declare no conflicts of interest.

\section{Ethics approval}

The Human Research Ethics Committee (Tasmania) approved the survey methodology and questionnaire content for the 2016 Tasmanian Population Health Survey (TPHS) in May 2016 (reference number: H0015759). The Tasmania Health and Medical Human Research Ethics Committee (HREC) approved the analysis of data for this study on 01 May 2019 (reference number: H0017848).

\section{Data accessibility}

The data that support the findings are stored at the Department of Health, Tasmania, Australia. Restrictions apply to the availability of these data. Requests for data may be directed to the custodians.

\section{Running head}

Active commuting in a regional/rural area

\section{Keywords}

Locomotion; Transportation; Exercise; Rural Health; Behavioral Research; Epidemiologic Factors; Cross-Sectional Studies

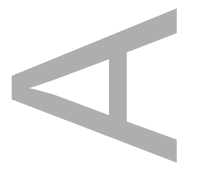


MR OLIVER STANESBY (Orcid ID : 0000-0002-5996-5881)

MRS KIM JOSE (Orcid ID : 0000-0002-9346-6429)

DR MELANIE SHARMAN (Orcid ID : 0000-0003-1949-4920)

Article type : Short Research Article

\title{
Socio-demographic, behavioural and health-related characteristics
} associated with active commuting in a regional Australian state: Evidence from the 2016 Tasmanian Population Health Survey

\author{
Abstract \\ Issue addressed \\ Physical activity is lower and rates of preventable common diseases are higher in \\ regional/rural than urban Australia. Active commuting (walking/bicycling to get from one \\ place to another) may benefit health through increased physical activity, but most evidence of \\ its correlates come from urban studies. This study aimed to investigate associations between \\ active commuting, socio-demographic characteristics, behaviours, total physical activity and \\ health in a regional/rural Australian state.
}

\section{Methods}

This study used data from the 2016 Tasmanian Population Health Survey, a representative cross-sectional self-report survey of 6,300 adults in Tasmania, Australia. Logistic regression modelling investigated associations between socio-demographic, behavioural and health characteristics and past week active commuting frequency.

\section{Results}

In multivariable models, being younger, having tertiary qualifications, living in a socioeconomically advantaged area, being physically active, having a healthy body mass index, and good/excellent self-rated health were associated with engaging in more active commuting. 
Inner regional dwellers were no more likely than outer regional dwellers to actively commute after covariate adjustment.

\section{Conclusion}

Strategies to promote active commuting in regional/rural areas might consider targeting older adults, those less educated, those living in socio-economically disadvantaged areas, those less physically active, those with poorer health, and those with higher body mass index. Research could further investigate why these groups appear to be less active for commuting purposes.

\section{So what?}

Increasing physical activity and active commuting may help to reduce rates of preventable common diseases in regional/remote areas.

\section{Keywords}

Locomotion; Transportation; Exercise; Rural Health; Behavioral Research; Epidemiologic Factors; Cross-Sectional Studies

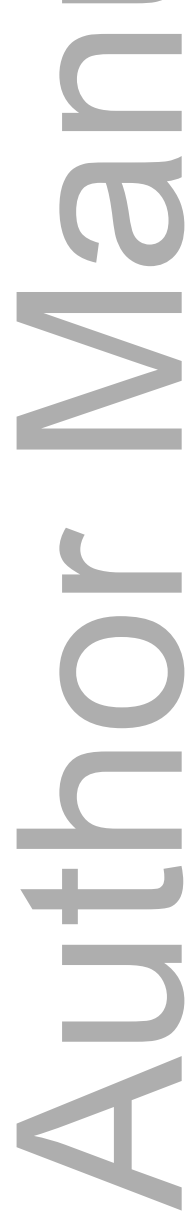




\section{Introduction}

Active commuting is physical activity (commonly walking and bicycling) undertaken for the purpose of getting from one place to another, including to get to and from public transport services (1). Doing more active commuting is associated with greater physical activity $(2,3)$. Given the widespread negative impacts of physical inactivity and the strong links between physical activity and health (4-9), promoting active commuting is a potentially valuable strategy for improving population health. Indeed, increased active commuting is associated with improved cardiorespiratory fitness, reduced all-cause mortality, reduced cancer mortality and morbidity, lower body weight, lower likelihood of hypertension and lower likelihood of diabetes $(2,10-13)$, and evidence from systematic reviews indicates active commuting specifically (rather than total physical activity) may have positive health outcomes $(14,15)$. Replacing motor vehicle transport with active commuting also provides numerous social, environmental and economic co-benefits such as improved air quality and reduced vehicle emissions, traffic congestion and dependency on fossil fuels $(10,16)$.

A large proportion of Australians do not meet the national physical activity guidelines and are insufficiently active. The proportion of residents who are sufficiently active is lower in regional/remote (i.e., rural) areas than urban areas. In 2014-2015, 40\% of Australian adults living in outer regional/remote areas were sufficiently active, compared to $43 \%$ in inner regional areas and $50 \%$ in urban areas $(17,18)$. Given the lower levels of physical activity and higher burden and rates of many preventable common diseases (e.g., cardiovascular diseases, some cancers, and type 2 diabetes (19)) in regional/remote areas, further research is required to better understand and promote physical activity and active commuting in these areas.

Understanding socio-demographic and behavioural correlates of active commuting is important for designing and tailoring strategies to promote physical activity and associated benefits. Research has identified some socio-demographic factors associated with active commuting, although this literature has mostly focussed on children and adolescents (20). There are no systematic reviews which consolidate the evidence on socio-demographic and behavioural correlates of active commuting among adults (most focus on built environment correlates; e.g., $(21,22)$ ). However, among samples including adults, being younger, belonging to a minority racial/ethnic group, and living in more densely-populated urban areas is associated with doing more active commuting $(13,23-27)$. A systematic review of European studies found no clear pattern of association between measures of socio-economic position and active commuting (28). 
To date, most epidemiological research investigating correlates of active commuting has been conducted in predominantly urban areas, with less attention given to those in regional/remote areas. Due to infrastructural, demographic, health, social, political and economic differences between urban and rural (i.e., outer regional/remote) areas, it is unclear how the barriers, enablers and health outcomes of active commuting in urban areas differ from those in regional/remote areas (29). Given the health disparities between regional/remote and urban dwelling adults, it is critical for health promotion that we understand the socio-demographic, behavioural and health characteristics associated with active commuting in regional/remote areas.

Therefore, among a representative sample of residents in the regional Australian state of Tasmania (all areas in Tasmania are classified as regional/remote with at least some restrictions to aceessibility to some goods, services and opportunities for social interaction, and there are no major cities), this study aimed to (i) investigate the socio-demographic and behavioural characteristics of those who use active commuting and those who do not; (ii) investigate whether doing more active commuting is associated with greater total physical activity; and (iii) investigate whether doing more active commuting is associated with better self-assessed general health. Based on existing knowledge from predominantly urban studies, we hypothesise: (i) younger adults and those living in less remote areas (higher density) will do more active commuting ; (ii) those doing more active commuting will be more physically active; and (iii) those doing more active commuting will report better health characteristics.

\section{Methods}

The Human Research Ethics Committee (Tasmania) approved the survey methodology and questionnaire content for the 2016 Tasmanian Population Health Survey (TPHS) in May 2016 (reference number: H0015759). The Tasmania Health and Medical Human Research Ethics Committee (HREC) approved the analysis of data for this study on 01 May 2019 (reference number: H0017848).

\section{Design and sample}

The TPHS is a three-yearly cross-sectional monitoring and surveillance survey of the health, lifestyles and well-being of a representative sample of adults from the Australian state of Tasmania (30). Tasmania is an island state situated south of the Australian mainland. Tasmania's median age of 42 years is the highest of all Australian States and Territories (31). The entirety of Tasmania's estimated 509,965 residents live in areas classified as inner regional, outer regional, remote or very remote $(32,33)$. As the largest urban centre, the city of Hobart, had a population of 178,009 residents in 2016, and no areas in Tasmania are 
classified as major cities (i.e., areas with relatively unrestricted accessibility to a wide range of goods, services and opportunities for social interaction). Most Tasmanian residents live in inner regional areas where there is some restriction upon accessibility to goods, services and opportunities for social interaction. The primary public transport company in Tasmania operates bus services in Hobart, Launceston and Burnie - three of the four largest cities in Tasmania $(33,34)$.

In 2016, 6,300 non-institutionalised Tasmanian residents aged 18 years and over were recruited to participate in the TPHS (response $=64.4 \%$ ). Computer Assisted Telephone Interviewing of participants was conducted between October and November. Sampling was completed via random digit dialling (RDD) of landline numbers, pre-screened RDD of Tasmanian mobile phone numbers and random selection from a commercially available list of Tasmania mobile numbers. Sampling was stratified by region (North, North West, South), age and gender.

Additional information about the 2016 TPHS methodology and a detailed description of the sample and the Tasmanian adult population is described elsewhere (30).

\section{Measures}

Active commuting (outcomes)

Respondents were asked to report their past week active commuting via the following item which was adapted from the Global Physical Activity Questionnaire (GPAQ) (35): 'In the LAST 7 DAY PERIOD, on how many days did you walk, run or bicycle for at least 10 minutes continuously to get to and from places? This includes walking to and from public transport.' Two variables were created from answers to this item. The first was a dichotomous variable classifying respondents as uses active commuting (one or more days per week; i.e., yes) or does not use active commuting (zero days per week; i.e., no). The second was a categorical variable classifying respondents as: (i) does not use active commuting (zero days per week; i.e., none); (ii) uses active commuting between one and three days per week (i.e., sometimes); or (iii) uses active commuting four or more days per week (i.e., regular).

Total physical activity

A series of questions adapted from the Active Australia Survey (36) asked respondents to report the number of times and total time they engaged in vigorous physical activity and other moderate physical activity in the last week. Total vigorous physical activity was calculated as the sum of time spent doing physical activity for recreation, exercise, sport or work which made the respondent breathe harder or puff and pant (excluding vigorous household chores, 
gardening and heavy work around the yard). Total moderate physical activity was calculated as the sum of time spent doing moderate physical activity for recreation, exercise, sport or work that was not already mentioned (e.g., gentle swimming, social tennis, golf).

Respondents were classified into one of three categories which described whether their physical activity in the last seven days met the 2014 Australian Physical Activity and Sedentary Behaviour Guidelines (18). The three categories were inactive (did not engage in any moderate or vigorous physical activity), insufficient physical activity (engaged in some moderate or vigorous physical activity but < sufficient) and sufficient physical activity (accumulated 150 to 300 minutes of moderate intensity physical activity or 75 to 150 minutes of vigorous intensity physical activity or an equivalent combination of both moderate and vigorous activities).

Self-reported socio-demographic, behavioural and health-related characteristics Socio-demographic characteristics reported were age, gender, highest level of education, current employment status, household composition, equivalised household income, relative socio-economic disadvantage, and remoteness of residence. Behavioural characteristics assessed were total physical activity, sedentary behaviour (sitting time), fruit and vegetable consumption, smoking status, and alcohol consumption. Health-related characteristics reported were self-assessed general health status, cardiometabolic risk score, body mass index (BMI), history of depression or anxiety, heart disease, stroke, cancer, osteoporosis, arthritis, high blood sugar levels, cataracts, glaucoma, diabetic eye disease or diabetic retinopathy, macular degeneration, as well as current asthma, hypertension, type 2 diabetes and depression or anxiety.

The survey items and methods used to derive these variables are described in detail in the online Supporting Information (Supporting Methods 1).

\section{Analysis}

All analyses were conducted on data from a sample of 6,300 Tasmania adults. Descriptive statistics (percentages and 95\% confidence intervals) were used to characterise the sample. Multivariable logistic regression modelling was used to investigate the association of sociodemographic, behavioural and health characteristics with any active commuting (binary logistic regression) and with frequency of active commuting (polytomous logistic regression). Forward stepwise elimination was used to select variables for inclusion in multivariable models. Covariates were retained in the multivariable regression models if they were significantly associated with the outcome in the multivariable model (indicated by $\mathrm{p}<0.05$ ). 
The likelihood ratio test (applied to unweighted data) was used as auxiliary evidence for covariate selection.

All estimates are weighted to adjust for participants' probability of being selected to participate and non-response (to account for differences in method of selection and to match the Tasmanian population distributions for age, gender, region and telephone status (30)). All reported counts (Ns) pertain to the unweighted sample. All associations reported in the text are statistically significant at the $95 \%$ confidence level (i.e., $\mathrm{p}<0.05$ ). All data analysis was completed in 2019-20 using Stata Statistical Software version 15.

\section{Results}

The sample is described in Table 1. The sample was similar to census estimates of the Tasmanian general population in terms of gender (51\% female vs. 51\% according to 2016 census data), age (11\% $18-24$ years vs. $6 \% 20-24 ; 30 \%$ vs. $23 \% 25-44 ; 35 \%$ vs. $28 \% 45-64$; $24 \%$ vs. $19 \% \geq 65)$, employment ( $7 \%$ vs. $4 \%$ unemployed) and household composition (34\% vs. $38 \%$ couple with children; $32 \%$ vs. $43 \%$ couple without children) (33). The sample was more educated (29\% vs. $16 \%$ tertiary; $9 \%$ vs. $11 \%$ < high school) and included fewer people living alone (14\% vs. $30 \%$ ) than the Tasmanian general population (33). Less than half (40.2\%) of respondents were sufficiently physically active, less than $20 \%$ (16.6\%) were insufficiently active and $43.2 \%$ were inactive. More than half of respondents did not engage in active commuting, $17.6 \%$ used active commuting sometimes (1-3 days/week) and 24.8\% used active commuting regularly ( $\geq$ four days/week). While findings are not comparable due to substantially different measures, $5.4 \%$ of Australians walk or cycle as the main form of commuting to work or study (37) and $21.1 \%$ of weekday trips in the Greater Hobart area are undertaken by walking or cycling (38).

[Table 1]

The univariable associations of socio-demographic, behavioural and health-related characteristics with active commuting are published in the online Supporting Information (Supporting Table 1) and summarised here. Age, gender, education, employment status, relative socio-economic disadvantage, remoteness of residence, equivalised household income, household composition, total physical activity levels, diet, smoking status, alcohol consumption, self-assessed general health status, cardiometabolic risk score, BMI, high blood pressure status, type II diabetes status, and history of heart disease, cancer, osteoporosis, arthritis and cataracts were associated with active commuting in the univariable logistic regression models. 
Table 2 presents the associations of socio-demographic, behavioural and health characteristics and active commuting after controlling for confounders (inclusion of variables determined via forward stepwise elimination). People living in the least socio-economically disadvantaged areas were over $60 \%$ more likely to engage in any active commuting and to use active commuting regularly but were no more likely than those in the most socioeconomically disadvantaged areas to use active commuting sometimes. Adults aged 18-24 years were more likely to use any active commuting and to use active commuting regularly. Those with higher levels of education were more likely than those with lower levels of education to sometimes use active commuting. Adults whose highest level of completed education was Technical and Further Education (TAFE), a trade certificate, or a diploma used active commuting less frequently than those with tertiary qualifications.

Being physically active was consistently associated with active commuting. Inactive respondents were less likely than those who engaged in insufficient or sufficient physical activity to use any active commuting, and also did so less frequently. Respondents with adequate vegetable consumption were more likely to regularly use active commuting.

Respondents who were overweight or obese were less likely than respondents with a healthy BMI to engage in any active commuting, and respondents who were obese were less likely to regularly use active commuting. Respondents who reported very good to excellent general health were more likely than those who reported poor or fair general health to sometimes use active commuting, but no less likely to regularly use active commuting. Respondents ever diagnosed with depression or anxiety were more likely than those with no history of depression or anxiety to regularly use active commuting.

[Table 2]

\section{Discussion}

This study identified several socio-demographic characteristics associated with active commuting and found doing more active commuting was associated with greater levels of physical activity and better self-assessed general health in a population-based representative sample of adults living in the regional Australian state of Tasmania. The findings are compared to previous epidemiological research which has tended to give more attention to urban than regional/rural areas.

\section{Is active commuting associated with greater levels of physical activity and favourable health characteristics?}

Being more physically active was associated with greater levels of active commuting among the sample of Tasmanian adults. This finding is consistent with those from most 
observational studies conducted in Australia and internationally among adults identified in a systematic review of the literature (2). This indicates active commuting may contribute to total physical activity rather than replace other forms of physical activity. However, as this was a cross-sectional study, we cannot establish the temporal order of occurrences or infer the direction of association. Therefore, (i) active commuting may lead to greater total physical activity (e.g., because active commuting is a form of physical activity); (ii) greater physical activity may lead to active commuting (e.g., because being physically fit makes active commuting easier or more feasible); or (iii) greater physical activity and active commuting may co-occur (e.g., because some people tend to engage in health-promoting behaviours, including physical activity and active commuting). Longitudinal approaches may tease out the direction of these associations, and a recent study by Kroesen and De Vos (39) suggests that BMI negatively influences later levels of active commuting (i.e., higher BMI is associated with lower later levels of active commuting).

We anticipated active commuting would be associated with more favourable health characteristics through physical activity. However, active commuting was associated with better self-assessed general health and healthy BMI even after controlling for total physical activity (meet the national guidelines) and a range of socio-demographic characteristics and behaviours. This finding indicates active commuting may be associated with some health benefits beyond those associated through increased physical activity, which is consistent with evidence from systematic reviews which indicate active commuting specifically (adjusting for other physical activity such as leisure time and occupational) may have positive health outcomes $(14,15)$.

In contrast, having ever been diagnosed with depression or anxiety was associated with regularly using active commuting, potentially because active commuting can be incorporated for additional physical activity to help manage anxiety and depression $(40,41)$. Previous cross-sectional research suggests a positive association between active commuting and mental health (42-45), and recent longitudinal research indicates that the positive effect of active commuting on later mental health is stronger than the effect of mental health on later active commuting (39). These findings from the literature contrast with the direction of association observed in this study, although this may be due to differences in the measures of mental health used.

\section{What factors are associated with doing more active commuting and how do the findings in this regional/remote setting compare to previous research?}


This study allows comparison of correlates of active commuting in a regiona $/$ remote setting to previous epidemiological research which has mostly focussed on predominantly urban areas.

Being a younger adult was associated with doing more active commuting. This may be due to young adults' limited access to cars/private transport compared to older adults, as car ownership peaks in mid-adulthood $(46,47)$. Also, while partly accounted for in our multivariable models through adjustment for total physical activity, self-assessed general health and BMI, younger adults may do more active commuting than older adults due to greater physical fitness, lower body fat percentage and fewer physical/health conditions that impede physical functioning (48-50). Further, as age increases, so does the likelihood of becoming a parent, which often requires complex travel patterns to transport children to care, school, or recreational or social activities.

Univariable analyses found respondents living in outer regional areas were less likely to actively commute and did so less frequently than those living in inner regional areas (as hypothesised; Supporting Table 1 of the online Supporting Information). Living in outer regional areas imposes lower accessibility to goods, services and opportunities for social interaction than inner regional areas $(32,51)$ (for example, in Tasmania, most inner regional dwellers have access to public transport services whereas many outer regional dwellers do not $(33,34))$. Thus, there may be less opportunity or incentive to actively commute in outer regional areas. However, inner regional dwellers were no more likely than outer regional dwellers to actively commute after adjusting for health, behavioural and socio-demographic characteristics. This contrasts with our hypothesis and findings from previous research which suggests a geographic gradient where living in non-metropolitan areas (lower accessibility to services) is associated with lower active commuting than in metropolitan areas (higher accessibility to services) independent of socio-demographic factors $(25,26)$. However, those studies compare urban with rural areas, whereas the current study compared regional/rural areas (i.e., inner vs. outer regional) which may explain the different findings (i.e. that the key difference for active commuting is the divide between metropolitan and all other nonmetropolitan areas rather than between differing levels of rurality/remoteness).

This study found respondents living in areas in the least disadvantaged quintile were more likely to actively commute than those living in areas in the most disadvantaged quintile. This study observed a positive association between education level and active commuting. Previous research shows an unclear pattern of association between measures of socioeconomic position and active commuting which may be explained by underlying factors (28, 
52, 53). Research in Sydney, Australia finds no clear relationship between neighbourhood socio-economic status and walkability (54). Less socio-economically disadvantaged areas (of Tasmania or regional/rural areas in general) may be more walkable or cyclable or have better access to public transport (55-57), thus encouraging active commuting. Further research is required to establish whether a consistent association between socio-economic status and active commuting exists in regional/rural areas. The potential moderating effect of socioeconomic status on the association between neighbourhood walkability and active commuting specifically in regional/rural areas warrants further investigation.

Irrespective of socio-economic status, the availability of safe, convenient and wellconnected walking and cycling infrastructure appears critical for supporting active modes of transport (58). Without sufficient accessible destinations, more trips will be made by motor vehicle, which will be more common in regional and rural areas due to their geographic dispersion. Limited public transport also impacts on active commuting, and regional and rural areas are typically poorer serviced than urban areas. Combined, these environmental and policy factors likely play an important role in active commuting behaviour, but were not assessed in the current study. Further research in regional and rural areas that captures these policy and environmental level variables, as well as social and individual level factors, is required to gain deeper insights into this issue.

\section{Limitations and strengths}

Due to the self-reported cross-sectional design, this study may be prone to recall and response biases (e.g., mis-estimation of physical activity from social desirability bias and inaccurate memory) (59), and the temporal nature of associations cannot be determined.

The active commuting variable also had some limitations that must be considered. Condensing the three GPAQ items on active transport (35) into a single survey question may have introduced some mismeasurement of active commuting and captures frequency but not duration or intensity of activity. However, a lack of comparable active commuting estimates among the Tasmanian general population means the presence and level of misestimation is unclear. It also does not capture instances in which the respondent walked, ran or cycled for less than 10 consecutive minutes to and from places, even if the sum of those instances was greater than 10 minutes. Discounting these instances may result in some mis-estimation of associations. The measure of active commuting meant we were unable to examine associations between the various exposure variables with walking and cycling separately, as our measure assessed 'active commuting' collectively. Given the environmental correlates of 
these behaviours can differ $(20,21,60)$, it is plausible that the demographic and healthrelated correlates may too.

It is likely some types of moderate physical activity were missed from the total physical activity measure because the question used to derive moderate physical activity asked about activities not already mentioned, and an earlier question asked about walking continuously for at least 10 minutes. This may increase the likelihood of observing positive associations between active commuting and total physical activity and favourable health characteristics. There may be other unmeasured variables (e.g., neighbourhood walkability; access to cars/private transport) that confound associations.

The high response of $64.4 \%$ is a strength of the 2016 TPHS, and the survey was weighted to those who were under-represented. As the TPHS aimed to capture a representative sample of Tasmanian adults, the results from this study are likely more generalisable to Australian regional/remote areas than most Australian population health surveys, but may not be generalisable to other areas (e.g., non-regional and non-western populations). This study paves the way and highlights a need for further longitudinal studies to discern temporality of associations and for use of more comprehensive measures of active commuting and specific health outcome measures, particularly in understudied regional/remote areas.

\section{Conclusion}

This study conducted in a regional Australian state found being younger, having tertiary qualifications, living in a socio-economically advantaged area, being physically active, having a healthy body mass index, and good/excellent self-rated health were associated with engaging in more active commuting. Inner regional dwellers were no more likely than outer regional dwellers to actively commute. While the cross-sectional nature of the study warrants cautious interpretation of the findings, strategies to promote active commuting in regional/rural areas might consider targeting older adults, those less educated, those living in socio-economically disadvantaged areas those less physically active, those with poorer health, and those with higher body mass index. Research could further investigate why these groups appear to be less active for commuting purposes. 


\section{References}

1. Australian Bureau of Statistics. Australian Health Survey: Physical Activity, 2011-12, 4364.0.55.004 Canberra, Australia: Australian Bureau of Statistics; 2015 [Available from: https://www.abs.gov.au/ausstats/abs@.nsf/Latestproducts/462FBA87B642FCA4CA257BAC 0015F3CE?opendocument.

2. Wanner M, Götschi T, Martin-Diener E, Kahlmeier S, Martin B. Active transport, physical activity, and body weight in adults: A systematic review. American Journal of Preventive Medicine. 2012;42(5):493-502.

3. Smith M, Hosking J, Woodward A, Witten K, MacMillan A, Field A, et al. Systematic literature review of built environment effects on physical activity and active transport-an update and new findings on health equity. International Journal of Behavioral Nutrition and Physical Activity. 2017;14(1):158.

4. Ezzati M, Rodgers A, Lopez A, Vander Hoorn S, Murray C. Mortality and burden of disease attributable to individual risk factors. In: Ezzati M, Lopez A, Rodgers A, Murray C, editors. Comparative quantification of health risks: Global and regional burden of disease attributable to selected major risk factors. Geneva, Switzerland: World Health Organization; 2004.

5. Lee I, Shiroma E, Lobelo F, Puska P, Blair S, Katzmarzyk P. Effect of physical inactivity on major non-communicable diseases worldwide: An analysis of burden of disease and life expectancy. The Lancet. 2012;380(9838):219-29.

6. Murray C, Lopez A. Global mortality, disability, and the contribution of risk factors: Global Burden of Disease Study. The Lancet. 1997;349(9063):1436-42.

7. World Health Organization. Global health risks: Mortality and burden of disease attributable to selected major risks. Geneva, Switzerland: World Health Organization; 2009. 8. World Health Organization. Global recommendations on physical activity for health. Geneva, Switzerland: World Health Organization; 2010.

9. Hallal P, Andersen L, Bull F, Guthold R, Haskell W, Ekelund U, et al. Global physical activity levels: Surveillance progress, pitfalls, and prospects. The Lancet. 2012;380(9838):247-57.

10. Rojas-Rueda D, de Nazelle A, Andersen Z, Braun-Fahrländer C, Bruha J, BruhovaFoltynova $\mathrm{H}$, et al. Health impacts of active transportation in Europe. PLOS ONE. 2016;11(3):e0149990. 
11. Oja P, Titze S, Bauman A, De Geus B, Krenn P, Reger - Nash B, et al. Health benefits of cycling: A systematic review. Scandinavian Journal of Medicine and Science in Sports. 2011;21(4):496-509.

12. Furie G, Desai M. Active transportation and cardiovascular disease risk factors in U.S. adults. American Journal of Preventive Medicine. 2012;43(6):621-8.

13. Gordon-Larsen P, Nelson M, Beam K. Associations among active transportation, physical activity, and weight status in young adults. Obesity Research. 2005;13(5):868-75. 14. Saunders L, Green J, Petticrew M, Steinbach R, Roberts H. What are the health benefits of active travel? A systematic review of trials and cohort studies. PLOS ONE. 2013;8(8):e69912.

15. Hamer M, Chida Y. Active commuting and cardiovascular risk: A meta-analytic review. Preventive Medicine. 2008;46(1):9-13.

16. Xia T, Zhang Y, Crabb S, Shah P. Cobenefits of replacing car trips with alternative transportation: A review of evidence and methodological issues. Journal of Environmental and Public Health. 2013;2013.

17. Australian Institute of Health and Welfare. Physical activity across the life stages. Cat. no. PHE 225.Canberra, Australia: Australian Institute of Health and Welfare; 2018.

18. Department of Health. Australia's physical activity and sedentary behaviour guidelines Canberra, Australia: Commonwealth of Australia; 2014 [Available from: https://www1.health.gov.au/internet/main/publishing.nsf/Content/fs-18-64years.

19. Australian Institute of Health and Welfare. Australian Burden of Disease Study: Impact and causes of illness and death in Australia 2015-Summary report. Australian Burden of Disease Study series no. 18. Cat. no. BOD 21. Canberra, Australia: Australian Institute of Health and Welfare; 2019.

20. Pont K, Ziviani J, Wadley D, Bennett S, Abbott R. Environmental correlates of children's active transportation: A systematic literature review. Health and Place. 2009;15(3):849-62.

21. Saelens B, Handy S. Built environment correlates of walking: A review. Med Sci Sports Exerc. 2008;40(7 Suppl):S550-S66.

22. Cerin E, Nathan A, van Cauwenberg J, Barnett D, Barnett A, on behalf of the Council on Environment and Physical Activity (CEPA) - Older Adults working group. The neighbourhood physical environment and active travel in older adults: A systematic review 
and meta-analysis. International Journal of Behavioral Nutrition and Physical Activity. 2017;14(1):15.

23. Whitfield G, Paul P, Wendel A. Active transportation surveillance-United States, 1999-2012. Morbidity and Mortality Weekly Report: Surveillance Summaries. 2015;64(7):117.

24. Yang Y, Diez Roux A, Bingham R. Variability and seasonality of active transportation in USA: Evidence from the 2001 NHTS. International Journal of Behavioral Nutrition and Physical Activity. 2011;8(1):96.

25. Patterson K, Cleland V, Venn A, Blizzard L, Gall S. A cross-sectional study of geographic differences in health risk factors among young Australian adults: The role of socioeconomic position. BMC Public Health. 2014;14(1):1278.

26. Hutchinson J, White P, Graham H. Differences in the social patterning of active travel between urban and rural populations: Findings from a large UK household survey. International Journal of Public Health. 2014;59(6):993-8.

27. Millward H, Spinney J. "Active living" related to the rural-urban continuum: A timeuse perspective. The Journal of Rural Health. 2011;27(2):141-50.

28. Beenackers M, Kamphuis C, Giskes K, Brug J, Kunst A, Burdorf A, et al. Socioeconomic inequalities in occupational, leisure-time, and transport related physical activity among European adults: A systematic review. International Journal of Behavioral Nutrition and Physical Activity. 2012;9(1):116.

29. Cleland V, Hughes C, Thornton L, Squibb K, Venn A, Ball K. Environmental barriers and enablers to physical activity participation among rural adults: A qualitative study. Health Promotion Journal of Australia. 2015;26(2):99-104.

30. Department of Health Tasmania. Report on the Tasmanian Population Health Survey 2016. Hobart, Australia: Department of Health Tasmania; 2016.

31. Australian Bureau of Statistics. 2016 Census: Tasmania: Media release: One in every five Tasmanians aged 65 years and over Canberra, Australia: Australian Bureau of Statistics; 2017 [Available from:

https://www.abs.gov.au/AUSSTATS/abs@.nsf/mediareleasesbyReleaseDate/7F1A862B6F8 B6BA0CA258148000A41AC?OpenDocument.

32. Australian Bureau of Statistics. Australian Statistical Geography Standard (ASGS):

Volume 5 - Remoteness Structure, July 2016 cat no. 1270.0.55.005. Canberra, Australia:

Australian Bureau of Statistics; 2018 [Available from:

https://www.abs.gov.au/ausstats/abs@.nsf/Latestproducts/1270.0.55.005Main\%20Features5J

This article is protected by copyright. All rights reserved 
$\underline{\text { uly } \% 202016 ? \text { opendocument } \& \text { tabname }=\text { Summary } \& \text { prodno }=1270.0 .55 .005 \& \text { issue }=\mathrm{July} \% 202}$ $016 \&$ num $=\& v i e w=$.

33. Australian Bureau of Statistics. 2016 Census QuickStats Canberra, Australia:

Australian Bureau of Statistics; 2019 [Available from:

https://quickstats.censusdata.abs.gov.au/census_services/getproduct/census/2016/quickstat/6.

34. Metro Tasmania. Who we are Hobart, Australia: Metro Tasmania; 2019 [Available from: https $/ /$ www.metrotas.com.au/corporate/who-we-are/.

35. World Health Organization. Global Physical Activity Questionnaire (GPAQ) analysis guide. Geneva, Switzerland: World Health Organization; 2012.

36. Australian Institute of Health and Welfare. The Active Australia survey: a guide and manual for implementation, analysis and reporting. Canberra, Australia: Australian Institute of Health and Welfare; 2003.

37. Australian Bureau of Statistics. Environmental Issues: Waste Management, Transport and Motor Vehicle Usage, Mar 2012. 4602.0.55.002. Canberra, Australia: Australian Bureau of Statistics; 2012.

38. Department of Infrastructure, Energy and Resources. Greater Hobart Household Travel Survey: Summary of analysis and key findings. Hobart, Australia: Department of Infrastructure, Energy and Resources, Tasmanian Government; 2010.

39. Kroesen M, De Vos J. Does active travel make people healthier, or are healthy people more inclined to travel actively? Journal of Transport \& Health. 2020;16:100844.

40. Craft L, Perna F. The benefits of exercise for the clinically depressed. Primary Care Companion to the Journal of Clinical Psychiatry. 2004;6(3):104.

41. Zschucke E, Gaudlitz K, Ströhle A. Exercise and physical activity in mental disorders: Clinical and experimental evidence. Journal of Preventive Medicine and Public Health. 2013;46(Suppl 1):S12.

42. Humphreys D, Goodman A, Ogilvie D. Associations between active commuting and physical and mental wellbeing. Preventive Medicine. 2013;57(2):135-9.

43. Roberts J, Hodgson R, Dolan P. "It's driving her mad": Gender differences in the effects of commuting on psychological health. Journal of Health Economics. 2011;30(5):1064-76.

44. St-Louis E, Manaugh K, van Lierop D, El-Geneidy A. The happy commuter: A comparison of commuter satisfaction across modes. Transportation Research Part F: Traffic Psychology and Behaviour. 2014;26:160-70. 
45. Sun Y, Liu Y, Tao F-B. Associations between active commuting to school, body Fat, and mental well-being: Population-based, cross-sectional study in China. Journal of Adolescent Health. 2015;57(6):679-85.

46. Nakanishi H, Black J. Travel habit creation of the elderly and the transition to sustainable transport: Exploratory research based on a retrospective survey. International Journal of Sustainable Transportation. 2016;10(7):604-16.

47. Delbosc A. Delay or forgo? A closer look at youth driver licensing trends in the United States and Australia. Transportation. 2017;44(5):919-26.

48. Shvartz E, Reibold R. Aerobic fitness norms for males and females aged 6 to 75 years: A review. Aviat Space Environ Med. 1990;61(1):3-11.

49. Hruby A,Hu F. The epidemiology of obesity: A big picture. Pharmacoeconomics. 2015;33(7):673-89.

50. Franceschi C, Garagnani P, Morsiani C, Conte M, Santoro A, Grignolio A, et al. The continuum of aging and age-related diseases: Common mechanisms but different rates. Front Med (Lausanne). 2018;5:61-.

51. Information and Research Branch, Department of Health and Aged Care. Measuring remoteness: Accessibility/Remoteness Index of Australia (ARIA). Revised edition ed. Canberra, Australia: Department of Health and Aged Care, Commonwealth of Australia; 2001.

52. Giles-Corti B, Donovan R. The relative influence of individual, social and physical environment determinants of physical activity. Social Science and Medicine. 2002;54(12):1793-812.

53. Teräslinna P, Partanen T, Koskela A, Oja P. Characteristics affecting willingness of executives to participate in an activity program aimed at coronary heart disease prevention. The Journal of Sports Medicine and Physical Fitness. 1969;9(4):224.

54. Cowie C, Ding D, Rolfe M, Mayne D, Jalaludin B, Bauman A, et al. Neighbourhood walkability, road density and socio-economic status in Sydney, Australia. Environmental Health. 2016;15(1):58.

55. Arundel J, Lowe M, Hooper P, Roberts R, Rozek J, Higgs C, et al. Creating liveable cities in Australia: Mapping urban policy implementation and evidence-based national liveability indicators. Melbourne, Australia: Centre for Urban Research (CUR) RMIT University; 2017. 
56. Manaugh K, El-Geneidy A. Validating walkability indices: How do different households respond to the walkability of their neighborhood? Transportation Research Part D: Transport and Environment. 2011;16(4):309-15.

57. Owen N, Cerin E, Leslie E, duToit L, Coffee N, Frank L, et al. Neighborhood walkability and the walking behavior of Australian adults. American Journal of Preventive Medicine. 2007;33(5):387-95.

58. Winters M, Buehler R, Götschi T. Policies to promote active travel: Evidence from reviews of the literature. Current Environmental Health Reports. 2017;4(3):278-85.

59. Prince S, Adamo K, Hamel M, Hardt J, Gorber S, Tremblay M. A comparison of direct versus self-report measures for assessing physical activity in adults: A systematic review. International Journal of Behavioral Nutrition and Physical Activity. 2008;5(1):56. 60. Muhs C, Clifton K. Do characteristics of walkable environments support bicycling? Toward a definition of bicycle-supported development. Journal of Transport and Land Use. 2016;9(2):147-88.

61. Pink B. Technical Paper: Socio-Economic Indexes for Areas (SEIFA) 2011, 2033.0.55.001. Canberra, Australia: Australian Bureau of Statistics, Commonwealth of Australia; 2013.

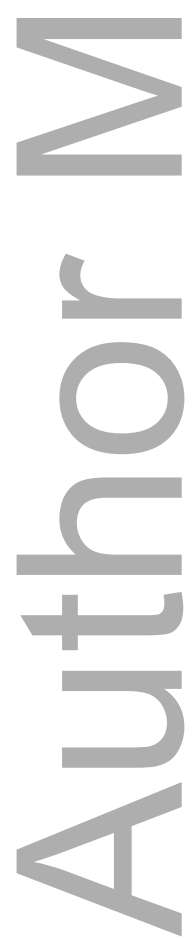




\section{Tables}

Table 1. Socio-demographic, behavioural and health-related characteristics of the sample of Tasmanian adults $(\mathrm{N}=6,300)$.

\begin{tabular}{|c|c|}
\hline Variable & $\%(95 \% \mathrm{CI})$ \\
\hline \multicolumn{2}{|l|}{ Socio-demographic characteristics } \\
\hline \multicolumn{2}{|l|}{ Age } \\
\hline $18-24$ years & $11.2(10.4,12.1)$ \\
\hline 25-34 years & $14.6(13.7,15.5)$ \\
\hline $35-44$ years & $15.4(14.5,16.3)$ \\
\hline $45-54$ years & $17.6(16.7,18.6)$ \\
\hline 55-64 years & $17.7(16.8,18.6)$ \\
\hline$\geq 65$ years & $23.5(22.4,24.6)$ \\
\hline \multicolumn{2}{|l|}{ Gender } \\
\hline Female & $50.7(49.4,52.0)$ \\
\hline \multicolumn{2}{|l|}{ Education } \\
\hline Tertiary & $29.4(27.6,31.4)$ \\
\hline Senior secondary college (matriculation) & $12.7(11.2,14.3)$ \\
\hline TAFE (with or without matriculation) & $31.0(29.1,33.0)$ \\
\hline High school & $17.8(16.3,19.5)$ \\
\hline$<$ High school & $8.6(7.7,9.6)$ \\
\hline Other & $0.4(0.2,0.8)$ \\
\hline \multicolumn{2}{|l|}{ Employment status } \\
\hline Employed for wages, salary or payment in kind & $46.1(44.0,48.1)$ \\
\hline Self-employed & $11.7(10.4,13.1)$ \\
\hline Unemployed & $4.3(3.4,5.3)$ \\
\hline Retired & $23.9(22.7,25.1)$ \\
\hline Unable to work & $4.9(4.1,5.8)$ \\
\hline Engaged in home duties, student or other & $9.2(7.9,10.7)$ \\
\hline \multicolumn{2}{|l|}{ Household composition } \\
\hline Couple only & $32.0(30.3,33.8)$ \\
\hline Couple with children & $34.3(32.3,36.3)$ \\
\hline One parent family & $9.9(8.6,11.4)$ \\
\hline One person & $14.3(13.0,15.7)$ \\
\hline Other (includes group) & $9.5(8.1,11.1)$ \\
\hline \multicolumn{2}{|l|}{ Remoteness } \\
\hline Inner regional & $81.5(80.1,82.9)$ \\
\hline Outer regional & $18.1(16.7,19.5)$ \\
\hline Remote & $0.4(0.2,0.6)$ \\
\hline \multicolumn{2}{|l|}{ Behavioural characteristics } \\
\hline \multicolumn{2}{|l|}{ Active commuting frequency } \\
\hline None (0 days/week) & $57.6(55.5,59.7)$ \\
\hline Sometimes (1-3 days/week) & $17.6(16.0,19.3)$ \\
\hline $\operatorname{Regular}(\geq 4$ days/week $)$ & $24.8(22.9,26.8)$ \\
\hline \multicolumn{2}{|l|}{ Physical activity } \\
\hline Inactive & $43.2(41.1,45.2)$ \\
\hline Insufficient & $16.6(15.0,18.4)$ \\
\hline Sufficient & $40.2(38.1,42.2)$ \\
\hline \multicolumn{2}{|l|}{ Diet } \\
\hline Adequate veget able consumption & $8.6(7.5,9.9)$ \\
\hline
\end{tabular}




\section{Health-related characteristics}

Self-assessed general health st atus

Excellent/very good

$37.7(35.6,39.8))$

Good

Fair/poor

Depression or anxiety

Ever diagnosed

$29.0(27.1,31.0)$

BMI

Underweight

$1.3(0.9,1.7)$

Healthy

$35.8(33.7,38.0)$

Overweight

Obese

$25.6(23.8,27.6)$

CI: confidence interval; Education: Highest level of education completed; Tertiary: University, Centre for Adult Education or some other Tertiary Institute degree, including post university (i.e., postgraduate diploma, Master's degree, PhD); Senior secondary college (matriculation): Year 12/higher school certificate/Tasmanian certificate of education/matriculation; TAFE: Technical and Further Education, trad e certificate, or diploma; SEIFA IRSD: SocioEconomic Indexes for Areas (SEIFA) Index of Relative Socio-economic Disadvantage (IRSD) 2011 (30, 61); Remoteness (of residence): Accessibility/Remoteness Index of Australia (ARIA) (51); Active commuting: Walk, run or bicycle for at least 10 minutes continuously to get to and from places (including public transport); Physical activity: Minutes of moderate and vigorous physical activity per week; Inactive: No moderate or vigorous physical activity; Insufficient physical activity: Some moderate or vigorous physical activity but < sufficient; Sufficient physical activity: Accumulate 150 to 300 minutes ( $2 \frac{1 / 2}{2}$ to 5 hours) of moderate intensity physical activity or 75 to 150 minutes ( $1 \frac{1 / 4}{4}$ to $2 \frac{1}{2} 2$ hours) of vigorous intensity physical activity or an equivalent combination of both moderate and vigorous activities (18); Adequate vegetable consumption (serves per day): $\geq$ five for women, $\geq$ six for men aged 19-50 years, $\geq 5.5$ for men aged 51-70 years, $\geq$ five for men aged $\geq 70$ years; BMI: Body mass index $\left(\mathrm{kg} / \mathrm{m}^{2}\right)$; Underweight: BMI < 18.5; Healthy: BMI = 18.5-<25; Overweight: $\mathrm{BMI}=25-<30$; Obese: $\mathrm{BMI} \geq 30 ;{ }^{\dagger} 10.2 \%$ of the sample had missing data for this variable.

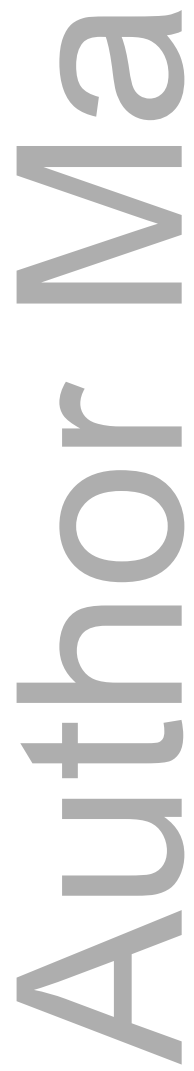


Table 2. Multivariable logistic regression model estimates of the relative odds and relative risk ratios of engaging in any active commuting (column 2) and frequency of active commuting (columns 3 and 4) according to socio-demographic, behavioural and healthrelated characteristics among the sample of Tasmanian adults.

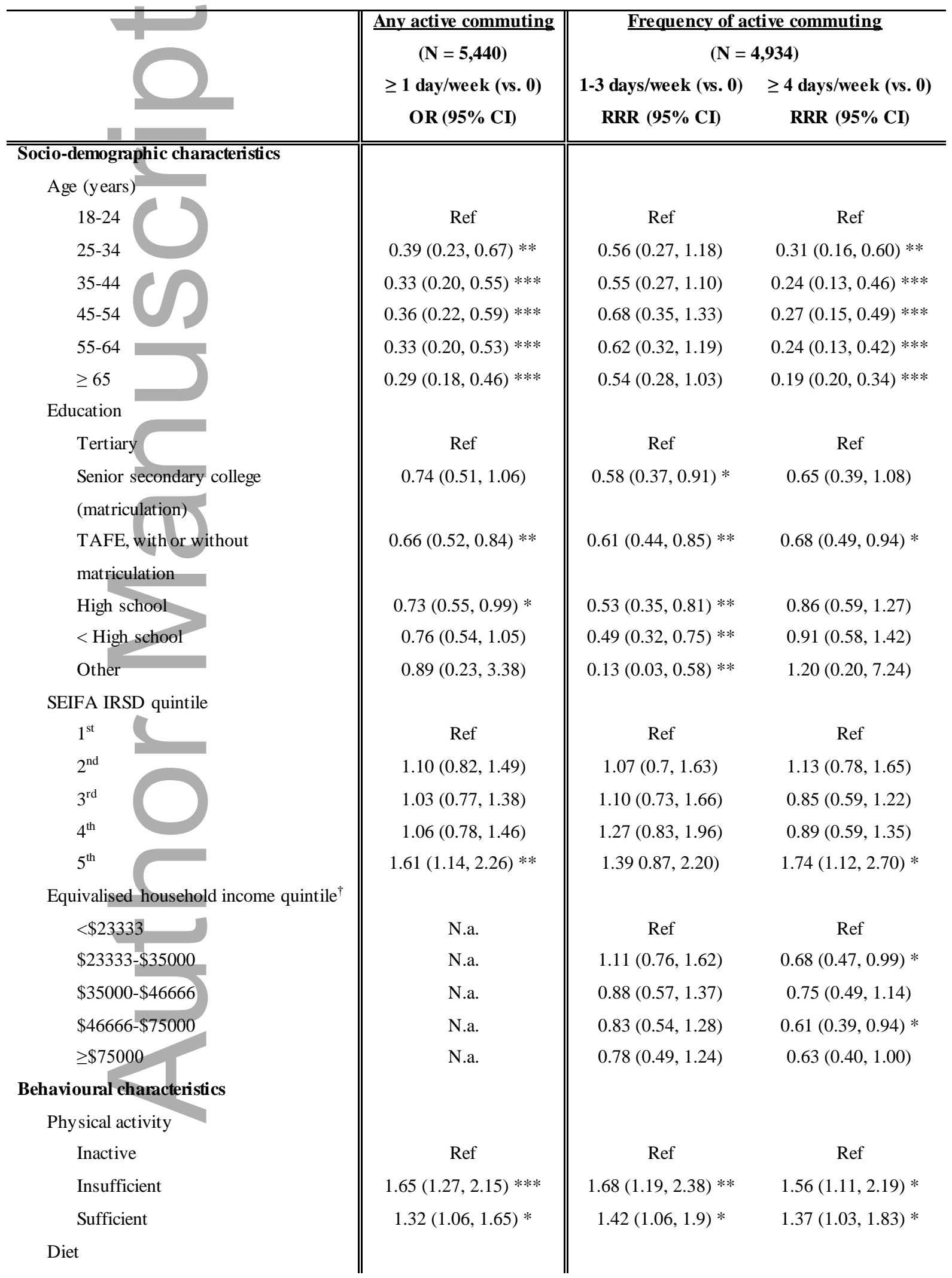


Inadequate vegetable consumption

Adequate vegetable consumption

\section{Heal th-related characteristics}

Self-assessed general health status

Excellent/very good

Good

Fair/poor

Depression or anxiety

Never diagnosed

Ever diagnosed

$\mathrm{BMI}^{*}$

Healthy

Underweight

Overweight

Obese

$$
\begin{aligned}
& \text { N.a. } \\
& \text { N.a. }
\end{aligned}
$$

Ref

Ref

$0.86(0.55,1.36)$

$1.75(1.21,2.54) * *$

Ref

Ref

Ref

$1.07(0.85,1.34)$

$0.74(0.57,0.97) *$

$1.03(0.76,1.4)$

$1.18(0.88,1.58)$

$0.64(0.43,0.96) *$

$0.85(0.60,1.21)$
Ref

N.a.

N.a.

$0.86(0.63,1.16)$

Ref

$0.45(0.16,1.31)$

$0.70(0.51,0.96)$ *

$0.97(0.68,1.38)$

Ref $1.35(1.02,1.78) *$

Ref

$0.86(0.40,1.85)$

$0.75(0.59,0.95) *$

$0.87(0.60,1.00)$ *

$* \mathrm{p}<0.05 ; * * \mathrm{p}<0.01 ; * * * \mathrm{p}<0.001$; OR: Odds ratio via multivariable logistic regression; RRR: Relative risk ratio via multivariable polyt tomous logistic regression; CI: Confidence interval; N.a.: Variable not retained in the multivariable model because it was not significantly associated with the outcome when added to the multivariable model during the forward stepwise covariate selection process; Active commuting: Walk, run or bicycle for at least 10 minutes continuously to get to and from places (including public transport);

Education: Highest level of education completed; Tertiary: University, Centre for Adult Education or some other Tertiary Institute degree, including post university (i.e., post graduate diploma, Master's degree, $\mathrm{PhD}$ ); Senior secondary co llege (matriculation): Year 12/higher school cert ificate/Tasmanian certificate of education/matriculation; TAFE: Technical and Further Education, trade certificate, or diploma; SEIFA IRSD: Socio-Economic Indexes for Areas (SEIFA) Index of Relative Socio-economic Disadvantage (IRSD) 2011 (30, 61); Phy sical activity: Minutes of moderate and vigorous physical activity per week; Inactive: No moderate or vigorous physical activity; Insufficient physical activity: Some moderate or vigorous physical activity but < sufficient; Sufficient physical activity: Accumulate 150 to 300 minutes ( $2 \frac{1}{2}$ to 5 hours) of moderate intensity physical activity or 75 to 150 minutes ( $1 \frac{1 / 4}{4}$ to $2 \frac{1}{2}$ hours) of vigorous intensity physic al activity or an equivalent combination of both moderate and vigorous activities (18); Adequate vegetable consumption (serves per day): $\geq$ five for women, $\geq$ six for men aged $19-50$ years, $\geq 5.5$ for men aged $51-70$ years, $\geq$ five for men aged $\geq 70$ years; BMI: Body mass index $\left(\mathrm{kg} / \mathrm{m}^{2}\right)$; Underweight: $\mathrm{BMI}<18.5$; Healthy: $\mathrm{BMI}=18.5-<25$; Overweight: $\mathrm{BMI}=25-<30$; Obese: $\mathrm{BMI} \geq 30 ;{ }^{\dagger} 10.9 \%$ of the sample had missing data for this variable; ${ }^{\star} 10.2 \%$ of the sample had missing dat a for this variable.

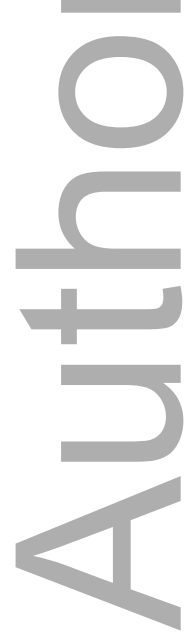




\section{University Library}

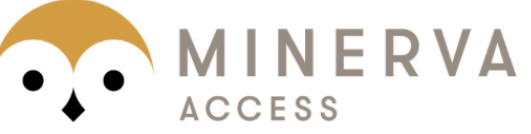

A gateway to Melbourne's research publications

Minerva Access is the Institutional Repository of The University of Melbourne

Author/s:

Stanesby, O;Long, M;Ball, K;Blizzard, L;Cocker, F;Greaves, S;Harpur, S;Johnston, F;Jose, K;Marshall, E;Palmer, AJ;Sharman, M;Venn, A;Williams, J;Cleland, V

Title:

Socio-demographic, behavioural and health-related characteristics associated with active commuting in a regional Australian state: Evidence from the 2016 Tasmanian Population Health Survey

\section{Date:}

2020-10-18

\section{Citation:}

Stanesby, O., Long, M., Ball, K., Blizzard, L., Cocker, F., Greaves, S., Harpur, S., Johnston, F., Jose, K., Marshall, E., Palmer, A. J., Sharman, M., Venn, A., Williams, J. \& Cleland, V. (2020). Socio-demographic, behavioural and health-related characteristics associated with active commuting in a regional Australian state: Evidence from the 2016 Tasmanian Population Health Survey. HEALTH PROMOTION JOURNAL OF AUSTRALIA, 32 (S2), pp.320-331. https://doi.org/10.1002/hpja.428.

Persistent Link:

http://hdl.handle.net/11343/276368 